\title{
Assessment of Inflammatory Markers in Keelvayu Nivarana Churunam (KNC) Supplementation to Carrageenan-Induced Inflammatory Rats
}

\author{
G. Vijayabaskar ${ }^{1}$ and V. Elango ${ }^{2^{*}}$ \\ ${ }^{1,2}$ Department of Siddha Medicine, Tamil University, Thanjvur, Tamil Nadu, India
}

Available online at: www.isroset.org

Received: 19/Nov/2018, Accepted: 12/Dec/2018, Online: 31/Dec/2018

\begin{abstract}
The carrageenan-induced paw edema is a well-defined model of acute inflammation that a variety of inflammatory mediators involves in its development and has wildly been used to evaluate the anti-inflammatory effect of natural products. The results of the current study suggested that KNC possessed anti-inflammatory effects in carrageenan-induced rats. The antiinflammatory mechanism of KNC may be related to the reduction of oxidative stress markers as MDA, GPx, Catalase and inflammatory markers PGE2, $\mathrm{NO}_{2}, \mathrm{TNF} \alpha$, IL6, IL-10, Myloperoxidase and IgM. Furthermore, the protective effect of KNC may result from anti-oxidative effects. Our findings provide new perspectives on the therapeutic use $\mathrm{KNC}$ in the management of inflammatory diseases including arthritis.
\end{abstract}

Keywords: Inflammatory mediators, Oxidative stress markers Keelvayu Nivarana Churunam (KNC)

\section{INTRODUCTION}

Inflammation is a complex process and is the response of the living tissues to injury. The inflammatory process involves enzyme activation of fluid, tissue breakdown and repair (Vane and Bolting, 1995). Acute inflammation is a process that involved the overproduction of free radicals, activation of a complex enzymes, and release of several inflammatory and pro-inflammatory mediators. The carrageenan-induced paw edema is a wellknown acute model of inflammation that is widely used for screening novel anti-inflammatory compounds. Carrageenan injection into the subplantar surface of rat paw induced a biphasic edema. The early phase observed around $1 \mathrm{~h}$ is related to the release of histamine, serotonin, bradykinin, and to a less extent prostaglandins produced by cyclooxygenase enzymes (COX), whereas the delayed phase (after $1 \mathrm{~h}$ ) is attributed to neutrophil infiltration, and the continuing of the prostaglandin generation (Gilligan et al., 1994). Release of the neutrophil-derived free radicals, nitric oxide (NO) and pro-inflammatory cytokines such as tumor necrosis factor (TNF- $\alpha$ ), and interleukin-1 $\beta$ (IL- $1 \beta$ ) also involved in the delayed phase of carrageenan-induced acute inflammation (Halici et al., 2007) Different observations suggest that drugs targeting inflammatory markers, free radical formation and pro-inflammatory protein expression (e.g. inducible nitric oxide synthase; iNOS) might provide a better control over inflammatory states than the therapeutic agents currently available (Ronchetti et al., 2009).

It is known that a variety of chemical substances act as anti-inflammatory agents and exert their effect through a spectrum of different modes of action (Arrigoni Mastelli,
1977) and that there is no remarkable correlation between their pharmacological activity and chemical structure (Sertie et al., 1990). The anti-inflammatory drugs currently available are probably polycomponent in that they are able to modulate more than one mediator or cellular event concerned with anti-inflammatory process (Whitehouse, 1974). The search for safe and effective anti-inflammatory drugs through the evaluation of medicinal plants known to be used in treatment of inflammation disorders will continue unabated. In the present study to evaluate the effect of Keelvayu Nivarana Churunam (KNC) in inflammatory mediators through carrageenan-induced rats.

\section{MATERIALS AND METHODS}

\section{Collection of plant}

The barks of Withania sonifera, Simlax china and roots of Hemidimus indicus and Alpenia officinanum were purchased from Traditional Medicinal shop, Thanjavur, Tamil Nadu, India. Healthy roots and barks were washed several times with distilled water to remove the traces of impurities from the roots. Shade dried at room temperature for about 10 days and ground in to fine powder using mechanical grinder. The powder was extracted with ethanol. A semi solid extract was obtained after complete elimination of alcohol under reduced pressure. The barks of Withania sonifera, Simlax china and roots of Hemidimus indicus and Alpenia officinanum extracts were stored in refrigerator until used.

\section{Preparation of plant extract}


The fine powder of barks of Withania sonifera, Simlax china and roots of Hemidimus indicus and Alpenia officinanum used for extraction. Three hundred grams $(300 \mathrm{~g})$ of the powered plants were extracted with ethanol (80\%) using Soxlet Apparatus. A semi solid extract was obtained after complete elimination of alcohol under reduced pressure. The extract was stored in refrigerator until used.

\section{Preparation of Keelvayu Nivarana Churunam}

Keelvayu Nivarana Churunam (KNC) prepared by the combination of Barks of Withania sonifera, Simlax china and roots of Hemidimus indicus and Alpenia officinanum taken in the ratio of 1:1:1:0.5 were used for further studies.

\section{Screening of Anti-inflammatory Activity}

Carrageenan induced paw edema in mice The effect of oral administration of $100 \mathrm{mg} / 100 \mathrm{~g}$ body weight of the extract of Keelvayu Nivarana Churunam, $40 \mathrm{mg} / \mathrm{kg}$ ibuprofen or vehicle (Saline, $10 \mathrm{ml} / \mathrm{kg}$ ) on the hind-paw oedema induced by sub plantar injection of $0.1 \mathrm{ml}$ Carrageenan $(1 \% \mathrm{w} / \mathrm{v})$ was evaluated according to the method described by Winter et al., (1962).8 In short, $0.1 \mathrm{~mL}$ of $1 \% \mathrm{w} / \mathrm{v}$ carrageenan was injected into the sub plantar tissue of left hind paw of each rat. Swelling of carrageenan injected foot was measured at $0,1,2,3 \mathrm{~h}$ using Mercury displacement method. Animals were treated with Keelvayu Nivarana Churunam extract 1hour before the carrageenan injection. Measurement was carried out immediately before and 3 hrs following carrageenan injection. Percent inhibition of test drugs was calculated in comparison with vehicle control (100\%). The oxidative stress and inflammatory markers measured in experimental rats.

Statistical analysis: Results were analyzed using One way analysis of variance (ANOVA) and expressed as Mean \pm SD. Data was further subjected to Dunnett's test and differences between means were regarded significant at $\mathrm{P}<0.05$.

\section{Biochemical estimation}

Malondialdehyde was estimated by the thiobarbituric acid assay method of Beuge and Aust (1978). The activity of catalase was assayed by the method of Beers and Sizer (1952). The activity of mitochondrial glutathione peroxidase was assayed by the method of Rotruck et al (1973). Nitric Oxide level was estimated by using the method of sastry et al., (2002). MPO activity in exudates was determined by the method as reported Graff et al., (1998). Immunoglobulins M (IgM) in serum were determined by single radial immunodiffusion (Mancini et al., 1965). Soluble immune complex was estimated by the method of Seth and Srinivas (Seth and Srinivas., 1981). This turbidometric assay was based on the precipitation of immune complex by low concentration of polyethylene glycol (PEG).

Measurement of TNF- $\alpha$, IL-6 and IL-10
Levels of inflammatory mediators (PGE2) and cytokines (IL-6, IL-10 and TNF- $\alpha$ ) from serum and ankle joint synovial fluids were determined by the research workers who were blind to the rat groups using ELISA Kits (Nanjing Jiancheng Technology Co., Ltd., Nanjing, China), according to the manufacturer's instructions. Samples were diluted using phosphate buffered saline $(\mathrm{pH}$ 7.4) prior to ELISA analysis if necessary. Results were expressed as $\mathrm{pg} / \mathrm{ml}$ for IL-6, IL-10 and TNF- $\alpha$ and PGE2 for $\mu \mathrm{g} / \mathrm{L}$.

\section{RESULTS AND DISCUSSION}

The carrageenan-induced paw edema is a welldefined model of acute inflammation that a variety of inflammatory mediators involves in its development and has wildly been used to evaluate the anti-inflammatory effect of natural products. Table.1: Effect of Keelvayu Nivarana Churunam (KNC) inflammatory markers in experimental rats. All the oxidative stress markers as MDA, GPx, Catalase and inflammatory markers $\mathrm{PGE}_{2}, \mathrm{NO}_{2}, \mathrm{TNF} \alpha$, IL6, IL-10, Myloperoxidase and $\mathrm{IgM}$ increased in carrageenan induced inflammatory rats. Supplementation of KNC to inflammatory rats reduced the level of inflammatory markers.

In order to provide a scientific explanation for the use of $\mathrm{KNC}$, we have investigated the biological effects of its extracts, mainly the ones related to the inflammatory process. The present data clearly showed that extracts of KNC have anti-inflammatory activity by the highly significant responses of some extracts on inhibiting the formation of oxidative stress and inflammatory markers after carrageenan subplantar injection. Moreover, this mediators released by stressed cells have effects on proinflammatory gene activation and chemokine induced proliferation producing oxidative stress markers as MDA, GPx, Catalase and inflammatory markers PGE2, NO2, TNF $\alpha$, IL6, IL-10, Myloperoxidase and IgM. The underlying factors that stimulate expression of these genes include oxidized lipids, reactive oxygen species (ROS), reactive nitrogen species (RNS) and advanced glycation end products (AGEs) (Goldberg, 2009).

\section{RESULTS}

\section{Table.1: Effect of Keelvayu Nivarana Churunam (KNC) inflammatory markers in experimental rats}

\begin{tabular}{|l|c|c|c|c|c|}
\hline \multirow{2}{*}{ Parameters } & \multicolumn{5}{|c|}{ Experimental rats } \\
\cline { 2 - 6 } & Normal & $\begin{array}{c}\text { Inflammatory } \\
\text { rat }\end{array}$ & & $\begin{array}{c}\text { Drug } \\
\text { treated }\end{array}$ & $\mathbf{2}$ \\
\hline $\begin{array}{l}\text { MDA (nmol of } \\
\text { MDA } \\
\text { formed/L) }\end{array}$ & 7.60 & 11.52 & 12.06 & 8.12 & 7.78 \\
\hline GPx (U/ml) & 8.62 & 6.13 & 6.88 & 8.10 & 8.70 \\
\hline Catalase (U/ml) & 6.40 & 4.04 & 4.11 & 5.94 & 6.30 \\
\hline PGE $_{\mathbf{2}}(\boldsymbol{\mu} \mathbf{g} / \mathbf{L})$ & 1.24 & 2.64 & 2.52 & 1.62 & 1.40 \\
\hline $\mathbf{N O}_{\mathbf{2}}(\boldsymbol{\mu M M} / \mathbf{L})$ & 31.40 & 52.30 & 56.14 & 36.33 & 34.17 \\
\hline
\end{tabular}




\begin{tabular}{|l|c|c|c|c|c|}
\hline TNF $\mathbf{( p g} / \mathbf{m l})$ & 9.74 & 18.46 & 16.25 & 10.50 & 10.04 \\
\hline IL6 (pg/ml) & 34.02 & 41.44 & 42.14 & 35.72 & 35.11 \\
\hline IL-10 (pg/ml) & 10.85 & 16.32 & 14.30 & 11.72 & 11.54 \\
\hline $\begin{array}{l}\text { Myloperoxidase } \\
\text { (U/ml) }\end{array}$ & 0.18 & 0.67 & 0.73 & 0.22 & 0.20 \\
\hline IgM (mg/ml) & 2.30 & 3.10 & 3.26 & 2.10 & 2.61 \\
\hline
\end{tabular}

on the therapeutic use $\mathrm{KNC}$ in the management of inflammatory diseases including arthritis.

\section{REFERENCES}

The first phase is due to release of histamine and serotonin. The second phase is caused by the release of bradykinin, protease, prostaglandin and lysosome. Based on this, it would be argued that suppression of $\mathrm{I}^{\text {st }}$ phase may be due to inhibition of release of early mediators, such a histamine, serotonin and action in second phase may be explained by an inhibition of cyclo-oxygenase. These mediators take part in inflammatory response and are able to stimulate nociceptive and thus reduce pain (Crunkhorn and Meacock, 1971). It has been reported that second phase of oedema is sensitive to most clinically effective anti inflammatory drugs, which has been frequently used to access the anti-oedematous effect of natural products.9 Based on these reports, it can be inferred that the inhibition effect of the extract of $\mathrm{KNC}$ on carrageenan induced inflammation in mice may be due to inhibition of the mediators responsible for inflammation.

Release of the neutrophil-derived free radicals, nitric oxide (NO) and pro-inflammatory cytokines such as tumor necrosis factor (TNF- $\alpha$ ), and interleukin-1 $\beta$ (IL-1 $\beta$ ) also involved in the delayed phase of carrageenan-induced acute inflammation (Halici et al., 2007) Different observations suggest that drugs targeting inflammatory markers, free radical formation and pro-inflammatory protein expression (e.g. inducible nitric oxide synthase; iNOS) might provide a better control over inflammatory states than the therapeutic agents currently available (Ronchetti et al., 2009).

A growing lines of evidence have demonstrated that flavonoids, phenolic acids, and triterpenoid possessed antiinflammatory effects in animal models (Arslan et al., 2010). Studies have also reported that flavonoids such as rutin, quercetin, luteolin produced significant anti-inflammatory activities (Deliorman Orhan et al., 2007). Hence, it was suggested that the antioxidant and anti-inflammatory activities of KNC may be related to its phenolic content.

In conclusion, the results of the current study suggested that KNC possessed anti-inflammatory effects in carrageenan-induced rats. The anti-inflammatory mechanism of KNC may be related to the reduction of oxidative stress markers as MDA, GPx, Catalase and inflammatory markers PGE2, NO2, TNFa, IL6, IL-10, Myloperoxidase and IgM. Furthermore, the protective effect of KNC may result from anti-oxidative effects. Our findings provide new perspectives
[1]. Feghali C. A., et al "Cytokines in acute and chronic inflammation", Frontiers in Bioscience, Vol- 2, 1997, pp 1226.

[2]. Arslan R, Bektas N, Ozturk Y. Antinociceptive activity of methanol extract of fruits of Capparis ovata in mice. J Ethnopharmacol 2010;131:28-32.

[3]. Deliorman Orhan D, Hartevioglu A, Küpeli E, Yesilada E. In vivo anti-infl ammatory and antinociceptive activity of the crude extract and fractions from Rosa canina L. fruits. J Ethnopharmacol 2007;112:394-400.

[4]. Halici Z, Dengiz GO, Odabasoglu F, Suleyman H, Cadirci E, Halici M. Amiodarone has anti-infl ammatory and antioxidative properties: An experimental study in rats with carrageenan-induced paw edema. Eur J Pharmacol 2007;566:215-21.

[5]. Ronchetti D, Borghi V, Gaitan G, Herrero JF, Impagnatiello F. NC $\times 2057$, a novel NO-releasing derivative of ferulic acid, suppresses infl ammatory and nociceptive responses in in vitro and in vivo models. Br J Pharmacol 2009;158:569-79.

[6]. Winter, C.A., Risley, E.A., Nuss, G.W. Carregeenin induced oedema in bind paw of the rat as assay for anti-inflammatory drugs. Experimental Biology and Medicine 1962 111:544547.

[7]. Crunkhorn P, Meacock SC. Mediators of the inflammation induced in the rat paw by Carrageenan. $\mathrm{Br} \mathrm{J}$ Pharmacol. 1971;42:392-402

[8]. Goldberg RB. Cytokine and cytokine-like inflammation markers, endothelial dysfunction, and imbalanced coagulation in development of diabetes and its complications. J Clin Endocrinol Metab, 2009; 94:31713182.

[9]. Beers R and Sizer I. (1952) A spectrophotometric method for measuring the breakdown of hydrogen peroxide by catalase. Journal of Biological Chemistry. 195: 133.

[10]. Graff G, Gamache DA, Brady MT, Spellman JM, Yanni JM. Improved myeloperoxidase assay for quantitation of neutrophil influx in a rat model of endotoxin-induced uveitis. J Pharmacol Toxicol Methods 1998, 39(3), 169-178.

[11]. Lowry O.H, Rosenbrough N.J, Farr A.L and Randall R.J.(1951) Protein measurement with the Folin's reagent. Journal of Biological Chemistry, 193: 265-276.

[12]. Mancini, G., Carbonara, A.O., Heremans, J.F. (1965). Immunochemical quantitation of antigens by single radial immunodiffusion. Immunochemistry; 2: 235-54.

[13]. Rodkey FL. (1965) Direct spectrophotometric determination of albumin in human serum. Clinical Chemistry 11: pp4789.

[14]. Rotruck JT, Pope AL, Ganther HE, Swanson AB, Hafeman DG and Hoekstra WG.(1973) Selenium biochemical roles as component of glutathione peroxidase. Science 179:588-590.

[15]. Sastry KVH, Moudgal RP, Mohan J, Tyagi JS and Rao GS. (2002) Spectrophotometric determination of serum nitrite and nitrate by copper-cadmium alloy; Analytical biochemistry, 306: 79-82.

[16]. Seth, P., Srinivas, R.V. (1981). Circulating immune complexes in cervical cancer - simple method for detection and characterization. Indian J Med Res; 73: 926-9.

[17]. Beuge JA and Aust SD. (1978) The thiobarbituric acid assay. Methods in Enzymology 52: pp 306-307. 
[18]. Arrigoni - Martelli, E., 1977. Prostaglandins , possible mechanism of anti-inflammatory drugs. In: Inflammation and Anti-inflammatorics. Spectrum, New York, p. 177.

[19]. Whitehouse, M.W., 1974. Introduction and background to the regulation of inflammation and then immune response. In , Scherrer, R.A., Whitehouse, M.W., (Eds.) Antiinflammatory Agents: Chemistry and Pharmacology. Academic Press, New York, p. 12.
[20]. Sertie, J.A., Basile, A.C., Panizza, S., Matida, A.K., Zelnik, R., 1990. Anti -inflammatory activity and sub - acute toxicity of artemetin. Planta Medico 56,36-40.

[21]. Gilligan JP, Lovato SJ, Erion MD, Jeng AY. Modulation of carrageenan-induced hind paw edema by substance P. Infl ammation 1994;18:285-92. 